\title{
Spatial and Genetic Analysis of a Flag Shoot Subpopulation of Erysiphe necator in Italy
}

\author{
Paolo Cortesi, Marie-Paule Ottaviani, and Michael G. Milgroom
}

First and second authors: Istituto di Patologia Vegetale, Università degli Studi di Milano, 20133 Milan, Italy; and third author: Department of Plant Pathology, Cornell University, Ithaca, NY 14853.

Accepted for publication 31 January 2004.

\begin{abstract}
Cortesi, P., Ottaviani, M.-P., and Milgroom, M. G. 2004. Spatial and genetic analysis of a flag shoot subpopulation of Erysiphe necator in Italy. Phytopathology 94:544-550.

Erysiphe necator overwinters as ascospores in cleistothecia and mycelium in dormant buds of grapevines. Shoots developing from infected buds early in the growing season are covered with dense mycelium and are known as "flag shoots". Combining epidemiological and genetic analyses, the objective of this study was to analyze the spatial and genetic structure of a flag shoot subpopulation of E. necator as a way to assess the contribution of flag shoots as primary inoculum, and to determine if flag shoot subpopulations are clonal with only one mating type. One vineyard in Tuscany, Italy was surveyed intensively for flag shoots for 8 years; isolations of E. necator were made from flag shoots for 5 years. We observed distinct disease foci developing around flag shoots early in epidemics, demonstrating a steep dispersal gradient of conidia and the importance of flag shoots as primary inoculum sources. Flag shoots were
\end{abstract}

ABSTRACT

Population biology of plant pathogens combining genetics and epidemiology has the potential to contribute to plant disease management (29). The combination of spatial and genetic analyses in particular, may be valuable for testing hypotheses about sources of inoculum, secondary spread of disease, and mode of reproduction $(7,9,21,27,36)$. Grape powdery mildew caused by Erysiphe necator Schw. (synonym Uncinula necator (Schw.) Burr.) (2) is an example of a plant disease in which genetic and epidemiological studies have been combined to reveal some interesting features relevant to disease management.

From an epidemiological perspective, E. necator has two distinct overwintering strategies and thus, two possible sources of primary inoculum. This fungus overwinters asexually as mycelium on green tissue of dormant buds. Early in the growing season (budbreak), the fungus grows and covers the developing shoot with dense mycelium. These developing shoots are called "flag shoots" (34). Flag shoots had been considered the principal source of primary inoculum before it was shown that E. necator can also overwinter sexually as ascospores in cleistothecia on the corky bark of grapevines (32). In New York, the fungus overwinters exclusively as cleistothecia (32), whereas in Europe, Australia, California, and South Africa overwintering as mycelium on susceptible cultivars is common $(19,33,35,41)$. In some locations

Corresponding author: P. Cortesi; E-mail address: paolo.cortesi@unimi.it

* The $e$-Xtra logo stands for "electronic extra" and indicates the HTML abstract available online contains supplemental material not included in the print edition. The online table contains allele frequencies of inter-simple sequence repeat markers in the flag shoot isolates of E. necator.

Publication no. P-2004-0331-01R

(C) 2004 The American Phytopathological Society spatially aggregated within and between years, most likely as a result of short-distance dispersal of conidia from flags early in the season when dormant buds for the next year's shoots are formed and are susceptible to infection. The two mating types were found in 1:1 ratios in this flag shoot subpopulation. Genotypic diversity, based on inter-simple sequence repeat markers, was high in all years with only two haplotypes occurring twice, and subpopulations were genetically differentiated between years. Similarities between haplotypes were not spatially autocorrelated. One multilocus analysis of population structure is consistent with the hypothesis of random mating but another is not. These results are not consistent with expectations for a strictly clonal or strictly randomly mating flag shoot subpopulation. Instead, the hypothesis that the flag shoot subpopulation of E. necator may reproduce clonally and sexually needs further testing.

Additional keywords: grape powdery mildew, overwintering, Uncinula necator, Vitis vinifera.

in Italy, primary inoculum derives from cleistothecia and overwintering mycelium, and the relative importance of each inoculum source varies according to location and weather conditions after budbreak $(6,10)$.

Studies of genetic diversity of E. necator have shown the existence of two genetically distinct subpopulations, or biotypes, corresponding to flag shoots in early infections and foliar isolates collected later in the growing season (12-14,23). The latter biotype was interpreted as having originated solely from ascospores released from overwintering cleistothecia $(12,23)$. As powdery mildew epidemics progress, flag shoot biotypes decline in frequency, and the late season biotype increases, which is consistent with expectations of their putative ecological differences $(14,23)$. Flag shoot subpopulations analyzed in France and Germany had only one mating type and appeared to constitute a single clonal lineage $(12,13)$, whereas flag shoot subpopulations in southern Italy comprised both mating types in approximately $1: 1$ ratios (23). Inferences about flag shoot subpopulations from these previous studies, however, are based on small samples from any one vineyard, making it difficult to analyze the multilocus population structure at vineyard scale. Furthermore, the correlation between biotype and timing during the epidemic may not hold in other populations. For example, a clonal lineage corresponding to Délye et al.'s (13) flag shoot biotype, was found also in Australia. However, in contrast to a flag shoot origin, these isolates were collected throughout the epidemic (between November and March) even though no mention was explicitly made of flag shoots in this study (38).

The overall objective of this study, therefore, was to analyze the spatial and genetic structures of a flag shoot population of E. necator in a single vineyard. Flag shoots have been shown to occur more often on the same vines than what would be expected 
at random $(35,41)$, possibly indicating local spread of secondary inoculum early in the epidemic while the majority of buds that give rise to the next year's shoots are formed and are still susceptible to infection (33). Therefore, our specific objectives with respect to spatial structure were to (i) describe foci of powdery mildew foliar infections surrounding flag shoots early in epidemics; and (ii) test whether flag shoots are spatially autocorrelated within and between years. Our objectives with respect to genetic structure were to test the hypothesis that flag shoot populations of E. necator persist clonally and consist of only one mating type. Specifically, we tested whether flag shoot genotypes are (i) monomorphic for mating type; (ii) persistent between years; (iii) spatially autocorrelated; (iv) consistent with expectations of random mating; and (v) genetically differentiated between years. To accomplish these goals, we intensively surveyed and mapped flag shoots in the same vineyard in Italy over an 8 -year period, and genotyped isolates of E. necator from flag shoots in 5 years for mating type and polymerase chain reaction (PCR)-based genetic markers.

\section{MATERIALS AND METHODS}

Study sites and sampling. Flag shoots were monitored annually from 1994 to 2001 in the commercial vineyard, Santa Cristina that is located in Montefiridolfi (Firenze Province), Tuscany. We studied this vineyard because it was previously shown to have a regular occurrence of flag shoots (11). The vineyard is approximately 1 ha in area, planted with Vitis vinifera cvs. Chardonnay and Malvasia lunga del Chianti, and cordon trained and spur pruned. Distances between rows and between vines were 3 and $1.2 \mathrm{~m}$, respectively. Vines of the two varieties were randomly distributed within the vineyard (data not shown) and were not significantly different for the number of flag shoots per ha, vines with flag shoots, or flag shoots per vine (10). We intensively surveyed an area ranging approximately from 0.15 to 0.35 ha. The first survey in 1994 included only 414 vines in 9 rows, expanded to 828 vines in 18 rows in 1995 and 1996, and expanded to 966 vines in 21 rows from 1997 to 2001 (Fig. 1). In all years, we visited this vineyard biweekly, beginning just after budbreak until all flag shoots had appeared. On the basis of past observations, all flag shoots appear in this region by early to mid June (10). All vines in the survey area were visually checked for the presence of flag shoots. The location of each vine with a flag shoot was recorded in all years.

We attempted to isolate E. necator from every flag shoot found from 1997 to 2001. One infected leaf was randomly collected from each flag shoot, and under the dissecting microscope with an eyelash fastened to a glass tube, a single-conidial chain was transferred from the infected leaf to a newly formed leaf of a $V$. vinifera seedling $\mathrm{cv}$. Riesling Italico grown in a sealed plastic cup in the greenhouse. One isolate per flag shoot was retained in this way, and to be sure to have single-conidial isolates, each isolate was submitted to two subsequent cycles of single-conidial chain transfer at 8-day intervals. Thereafter, mass transfers of conidia collected on an eyelash passed through the mycelium to new seedlings were done at 2- to 3-week intervals to maintain cultures. We obtained a total of 81 flag shoot isolates over 5 years. The 1997 and 1998 samples used to determine population genetic structure comprised of 27 and 34 isolates, respectively, representing 24 and $38 \%$ of the flag shoots observed each year.

In 1997, incidence and severity of powdery mildew was monitored in the vicinity of two randomly chosen flag shoots (flag shoot 1 [Fs1] was in row 5 on vine 20; flag shoot 2 [Fs2] was in row 11 on vine 21). For each of these two flag shoots, we assessed disease on 21 vines (the vine with the flag shoot, three vines in the same row on each side of the vine with the flag shoot, and the seven corresponding vines in rows on either side of the row with the flag shoot). As a control, we monitored disease on
21 vines (vines 2-8 in rows 3-5), approximately $10 \mathrm{~m}$ from the nearest flag shoot in the plot. Monitoring was done on three dates, 19 May, 1 June, and 12 June. For each assessment, we visually checked all leaves of 10 shoots per each vine. Disease incidence (as percent of infected shoots) and severity (as percent infected leaf area) (6) were estimated.

\section{Row \#}

\begin{tabular}{|c|c|c|c|c|c|c|c|c|c|c|c|c|c|c|c|c|c|c|c|c|}
\hline line \# & $-c$ & & & & & & & & & & & & & & & $=$ & & ? & ㅇํ & \\
\hline 1 & . & & · . & . . & & & . . & . & & . & . & . & . & . & . & . & . & . & & 1 \\
\hline 2 & . & . 1 & 1. & . . & & & . & . & & . & . & . & . & . . & . & . & . & . & . & . \\
\hline 3 & . & . & . . & . . & & & . & . & & . & . & . & . & . & . & . & . & . & $\cdot$ & . \\
\hline 4 & . & . . & . . & . . & . & & . & . . & & . & . & . & . & . . & . & . & . & . & . & . \\
\hline 5 & . & . . & - . & . . & & & . & - . & & . & . & . & . & . . & . & . & . & . & . & . \\
\hline 6 & . & . . & . . & . . & & & . & . . & & . & . & . & . . & . 1 & . & . & . & . & & 1 \\
\hline 7 & . & . . & . 1 & . & & & . & . . & 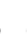 & . & . & . & . . & . 1 & . & . & . & . & . & . \\
\hline 8 & . & . . & . . & . . & & & . & . . & & . & . & . & . & . . & . & . & . & . & . 1 & 1 \\
\hline 9 & . & & 1 & . & & & . & . . & & . & . & & 3 & 3. & . & . & . & . & 11 & 1 \\
\hline 10 & . & . . & . . & . . & 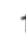 & & 2 & 2 . & & . & 2 & 1. & . . & . . & . & . & 3 & & 2 & . \\
\hline 11 & 1 & . . & . & . . & & & . & . & & . & . & . & . 2 & & 1 & 1 & . & . & . & . \\
\hline 12 & . & . . & . & . . & & & . & . . & & . & . & . & · . & . 1 & . & 3 & . & . & 1 & . \\
\hline 13 & . & . . & . & . . & & & . & . . & & . & . & 1 & 1 . & . . & . & 5 & . & . & . & . \\
\hline 14 & . & & . & . . & & &. & . & . & . & 1 & 1. & . & . & . & . & . & . & . & . \\
\hline 15 & . & . . & . & . . & & &. & . . & . & . & $\cdot$ & 1. & . 1 & 1. & 4 & . & 4 & . & . & . \\
\hline 16 & 1 & . & . & . . & & &. & . . & &. & 2 &. & . 1 & 1. & . & . & . & . & . & 1 \\
\hline 17 & . & & 1. & . 2 & & 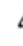 & 4. & . . & . &. & 2 & . & . . & . & . & . & . & . & . & . \\
\hline 18 & . & . & . . & . 3 & 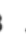 & & 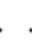 & . . & . & . & 1 & 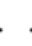 & . . & . & . & . & . & . & . & . \\
\hline 19 & . & & . . & .2 & 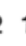 & 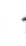 & 1. & . . & & . & . & 3 & 3. & . & . & . & . & . & . & . \\
\hline 20 & . & . & . & 3 & 3 & & . . & . . & . & . & 1 & . 1 & 1. & . & . & 3 & . & . & . & . \\
\hline 21 & . & & . . & . 2 & & & 1. & . . & . & . & 1 &. & . . & - . & 2 & . & 1 & . & & 1 \\
\hline 22 & . & . & . . & . . & & & . & . . & & 1 & 1 & . & . . & 3 & 2 & 1 & 1 & . & . & . \\
\hline 23 & . & & 1 & . . & 2 & 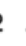 &. & . . & . & $\cdot$ & 1 & & 22 & 21 & . & 4 & . & . & 1 & . \\
\hline 24 & . & . & . . & . 1 & 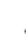 & &. & . . & & . & 1 & . & . . & . . & . & 2 & . & . & . & . \\
\hline 25 & . & & . 2 & 21 & 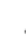 & & 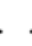 & . . & & . & . &. & . 4 & 4. & . & . & . & . & . & . \\
\hline 26 &. & & . 2 & 2. & & & . . & . 1 & & . & . & $\cdot 1$ & 1 . & & 2 & . & . & . & . & . \\
\hline 27 &. & & 1. & . . & & & . &. & . & . & . & . & . & . . & . & . & . & . & . & . \\
\hline 28 & . & . & . 1 & 11 & & & 1. & . . & . & . &. & 1. & . . & . & 1 & . & 1 & . & . & . \\
\hline 29 & . & . & . 1 & 1. & & & . & . & . & . & . & . & . . & . & 1 & . & 2 & . & . & . \\
\hline 30 & . & & . 2 & 2 . & & & . & . . & . & . & . & . & . . & . 3 & 4 & . & . & . & . & . \\
\hline 31 & . & . & . . & . & & 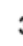 & 3. & . . & . & . & . & 1 & . . & . 1 & 2 & . & . & . & . & . \\
\hline 32 & . & . & . . & . . & & 7 & 7 . & . . & . & . & 1 & . & 2 & 2 . & . & . & . & . & . & . \\
\hline 33 & . & & 1. & . . & & & 1. & . . & . & . & . & . & 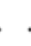 & . . & . & . & . & . & . & . \\
\hline 34 & . & . & . . & . & & & . & . & . & 1 & . & . & .2 & 2 . & . & . & . & . & . & . \\
\hline 35 & . & . & . 1 & 1. & & & 13 & 3. & . & . & . & . &. & . . & . & . & . & . & . & . \\
\hline 36 &. & & 11 & 1. & & & 11 & 1. & . & . & . & . & . & . . & . & . & . & . & . & . \\
\hline 37 & . & . & . . & . . & & 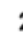 & 2 & . & . & . & . & . & 1. & . & . & . & . & . & . & . \\
\hline 38 & . & . & . . & . 1 & & & . & . & . & . & . & . & . & . . & . & 2 & . & 1 & & . \\
\hline 39 & . & . & . & . . & & & 21 & 1 . & . & . & . & . & . & . . & . & . & . & . & . & . \\
\hline 40 & $\cdot$ & . & . & . . & & & . & . . & . & . & . & . & . & . & . & . & . & . & . & . \\
\hline 41 & 1 & & . & . & & & . & . & . & . & $\cdot$ & 1 & 1 . & . . & . & . & . & . & . & . \\
\hline 42 & 4 & 2 & . & . & & & . & .1 & 1 & . & . & . & . & . . & . & . & . & . & . & . \\
\hline 43 & . & . & . & . & & & . & . & $\cdot$ & . & . & . & . & . & . & . & . & . & . & . \\
\hline 44 & . & & . . & . & & & . & . & & . & . & & & . . & & & . & . & - & . \\
\hline 45 & . & & . & . & & & . & . & & & . & . & . & • & & . & . & 1 & . & . \\
\hline 46 & $\cdot$ & & & & & & & & & & & & & & & & & & & . \\
\hline \multicolumn{21}{|l|}{1994} \\
\hline 1996 & & & & & & & & & & & & & & & & & & & & \\
\hline
\end{tabular}

Fig. 1. Map of grapevines surveyed for flag shoots of E. necator in the Santa Cristina vineyard from 1994 to 2001. Numbers at each vine show the number of years in which each vine had one or more flag shoots; dots indicate no flag shoots observed on that vine. Note that the number of rows surveyed increased during the course of the study, as indicated by the patterned bars below the map. 
Mating type assay. E. necator is heterothallic and has two mating types $(13,15,18,24)$. To determine mating type, we used methods described previously $(18,24)$ with minor modifications. We inoculated pairs of isolates on single leaves of $V$. vinifera seedlings cv. Riesling Italico grown in sealed plastic cups in the greenhouse and monitored them for production of cleistothecia. We mated 13 isolates of E. necator randomly sampled from the Fornace vineyard located in Montalcino (Siena Province) (unpublished) in all combinations including selfs. Plants were checked for the presence of cleisthothecia weekly for 3 weeks, starting 1 month after inoculation; the viability of ascospores in mature cleistothecia was assessed with fluorescein diacetate as described previously (8). Subsequently, two isolates of each mating type were used as testers (isolates M20 and M23 and M22 and M26 were arbitrarily assigned as MAT- and MAT+, respectively,) for mating with the 81 isolates from Santa Cristina with the same methods.

Genetic markers. We genotyped each isolate using the intersimple sequence repeat (ISSR) markers as described by Stummer et al. (38). Conidia and mycelium grown for 10 to 15 days on grape leaves were harvested with a cyclone separator connected to a vacuum pump; DNA was extracted as previously described (16). PCR amplification was completed with two microsatellite primers, $(\mathrm{GACA})_{4}$ and $(\mathrm{CAC})_{5}$, the primers for the core sequence of M13 minisatellite DNA (37), and the intron-splice junction primer, R1 (39). Reactions were performed in a total of $25 \mu \mathrm{l}$ containing $1 \times$ reaction buffer (Promega, Milan, Italy), $200 \mu \mathrm{M}$ of each nucleotide triphosphate, $1.5 \mathrm{mM} \mathrm{MgCl}_{2}, 150 \mathrm{ng}$ of microsatellite and M13 primers or $100 \mathrm{ng}$ of $\mathrm{R} 1$ primer, $1 \mu \mathrm{l}$ of $50 \mu \mathrm{l} \mathrm{ex}-$ tracted fungal DNA, and $1.5 \mathrm{U}$ of Taq DNA polymerase (Promega, Milan, Italy). PCR reactions were performed as described previously (38) with the i-Cycler Bio-Rad Laboratories thermalcycler (Milan, Italy). PCR products were analyzed by electrophoresis in 2\% agarose gels in Tris-borate-EDTA buffer stained with ethidium bromide. DNA amplifications were performed twice from a sample of independent DNA preparations to insure the repeatability of the markers used. For each replication, harvesting of fungal tissue and DNA preparations were conducted at different times to ensure independence.

Spatial autocorrelation analyses. Spatial analyses were conducted to test whether flag shoots and genetic similarity of flag shoot isolates were spatially autocorrelated. All analyses were completed with programs written in the $\mathrm{C}++$ programming language with minor variations on those used previously $(7,9,21,27$, 28 ). First, we tested whether vines with flag shoots are spatially autocorrelated within years by testing the hypothesis that the mean distance between flag shoots is not different from the mean distance when flag shoots are assigned to vines at random. Second, we tested whether the same vines had flag shoots in consecutive years more often than it would be expected at random. Third, we tested the hypothesis that the mean distance between flag shoots in one year and flag shoots in the previous year is not different from the mean distance when flag shoots are assigned to vines at random. To estimate $P$ values for these three tests, we generated null distributions by randomly assigning flag shoots to vines 1,000 times and, for each randomization, calculating the mean distance among flag shoots within years, the number of vines with flag shoots in consecutive years, or the mean distance among flag shoots between years, respectively.

Spatial autocorrelation of genetic data was conducted in two ways. First, we checked whether the same ISSR haplotypes persisted in vines in which flag shoots were found in successive years. Second, we analyzed whether the genetic distance between haplotypes of flag shoot isolates were spatially autocorrelated within and between years. This was completed by testing the hypothesis that genetic distance between isolates within years was correlated to the distance between the vines from which they were sampled $(21,27)$. We also tested the hypothesis that genetic distances between isolates were correlated to the distances between vines from which each isolate was collected in consecutive years. Genetic distance was calculated as $1-S_{\mathrm{xy}}$, in which $S_{\mathrm{xy}}$ is estimated as $2 N_{\mathrm{xy}} /\left(N_{\mathrm{x}}+N_{\mathrm{y}}\right)$, and $N_{\mathrm{x}}$ and $N_{\mathrm{y}}$ are the number of ISSR bands in isolates $\mathrm{X}$ and $\mathrm{Y}$, respectively, and $N_{\mathrm{xy}}$ is the number of bands shared by $\mathrm{X}$ and $\mathrm{Y}$. As above, 1,000 randomizations of haplotypes to locations were done for significance testing.

Population structure analyses. We analyzed the population structure of E. necator within and between years using the program of MultiLocus 1.2 (P.-M. Agapow and A. Burt, Department of Biology, Imperial College, Silwood Park, U.K.). For these tests, we used only loci with frequencies of ISSR bands $\geq 0.05$ or $\leq 0.95$ to avoid skewed loci (similar results were obtained with all loci; results not shown). Two different parameters were analyzed within subpopulations to test for evidence of recombination. First, we looked for pairs of loci with all four two-locus genotypes (the "four-gamete" test); this is also called phylogenetic incompatibility (1). Second, we estimated the index of association $\left(I_{\mathrm{A}}\right)(3,22)$ to test the hypothesis that populations were randomly mating. Hypothesis testing for both was done by 1,000 randomizations $(5,26)$. To test for genetic differentiation among years, we used Weir's $\theta$ (40) to estimate the genetic diversity attributable to differentiation among subpopulations $\left(F_{\mathrm{ST}}\right)$. Furthermore, we tested whether genetic similarity $\left(S_{\mathrm{xy}}\right)$ was greater within years than between years by assigning haplotypes to years at random 1,000 times.

\section{RESULTS}

During the 8 years of this survey, we observed 217 flag shoots, varying from 2 to 114 each year (Table 1; Fig. 1). Only 135 vines had flag shoots because 49 vines had flag shoots in two or more years. Flag shoots occurred in two consecutive years on the same

TABLE 1. Incidence and spatial autocorrelation of vines with flag shoots of Erysiphe necator in the Santa Cristina vineyard

\begin{tabular}{|c|c|c|c|c|c|c|c|c|c|}
\hline \multirow[b]{2}{*}{ Year } & \multirow[b]{2}{*}{$\begin{array}{c}\text { Vines } \\
\text { surveyed }\end{array}$} & \multirow[b]{2}{*}{ Flag shoots } & \multirow[b]{2}{*}{$\begin{array}{l}\text { Vines with } \\
\text { flag shoots }\end{array}$} & \multicolumn{3}{|c|}{ Spatial autocorrelation within years ${ }^{a}$} & \multicolumn{3}{|c|}{ Spatial autocorrelation between years ${ }^{b}$} \\
\hline & & & & $\begin{array}{l}\text { Observed } \\
\text { distance }\end{array}$ & $\begin{array}{l}\text { Random } \\
\text { distance }\end{array}$ & $P$ & $\begin{array}{l}\text { Observed } \\
\text { distance }\end{array}$ & $\begin{array}{l}\text { Random } \\
\text { distance }\end{array}$ & $P$ \\
\hline 1994 & 414 & 3 & 3 & 27.62 & 22.05 & 0.745 & $\ldots{ }^{\mathrm{c}}$ & $\ldots$ & $\ldots$ \\
\hline 1995 & 828 & 57 & 36 & 19.87 & 28.49 & $<0.001$ & $\ldots$ & $\ldots$ & $\ldots$ \\
\hline 1996 & 828 & 33 & 28 & 18.81 & 28.47 & $<0.001$ & 19.18 & 27.57 & $<0.001$ \\
\hline 1997 & 966 & 114 & 74 & 26.95 & 30.80 & $<0.001$ & 23.44 & 26.46 & $<0.001$ \\
\hline 1998 & 966 & 89 & 54 & 26.08 & 30.84 & $<0.001$ & 28.13 & 29.50 & 0.009 \\
\hline 1999 & 966 & 16 & 12 & 24.83 & 30.75 & 0.018 & 25.24 & 29.36 & 0.006 \\
\hline 2000 & 966 & 12 & 8 & 20.19 & 30.79 & 0.002 & 23.01 & 28.29 & $<0.001$ \\
\hline 2001 & 966 & 2 & 2 & 21.63 & 30.54 & 0.328 & 18.65 & 29.20 & 0.050 \\
\hline
\end{tabular}

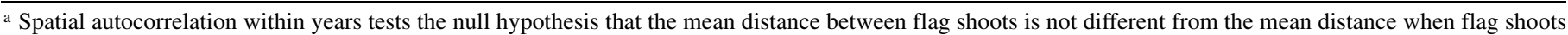
are assigned to vines at random. $P$ values are based on 1,000 randomizations.

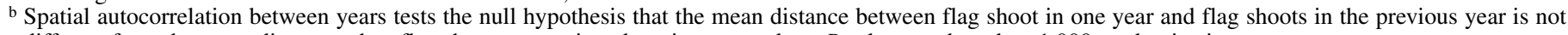
different from the mean distance when flag shoots are assigned to vines at random. $P$ values are based on 1,000 randomizations.

c ... = Not tested. 
vines 71 times. Some vines had flag shoots as many as 4 to 7 years in a row, indicating that shoot infections are persistent in some vines or some vines are more prone to flag shoot infections than others.

Disease focus expansion. Distinct disease foci were evident on the vines surrounding flag shoots in 1997 (Fig. 2). Flag shoots were first observed on 6 May. By 19 May, the two randomly chosen vines with flag shoots had 40 and $100 \%$ of their shoots with powdery mildew colonies. By this date, disease also was observed on the vines closest to those with the flag shoots, with 6 and 8 vines of 20 surveyed showing infections, respectively. At all survey dates, disease incidence and severity were typically higher on vines in the same row as the flag shoot compared with ad- jacent rows (Fig. 2). In contrast, powdery mildew incidence and severity were much lower on the control vines (without a flag shoot) on 19 May, even after two predicted ascospore infection events (17) (unpublished observations). On 1 June, we discovered a flag shoot just outside the control plot (vine 9 in row 4). The incidence of powdery mildew in the control plot had increased almost to the level observed around flag shoots; however, severity was still much lower. On 12 June, all shoots were infected around the flag shoots, as well as on the control vines; overall disease severity of the control plot was $22 \%$, while the average severity around the flag shoots was 18 and $21 \%$ (Fig. 2). The flag shoot that was found on 1 June just outside the control plot appears to have caused greater disease on nearby vines.
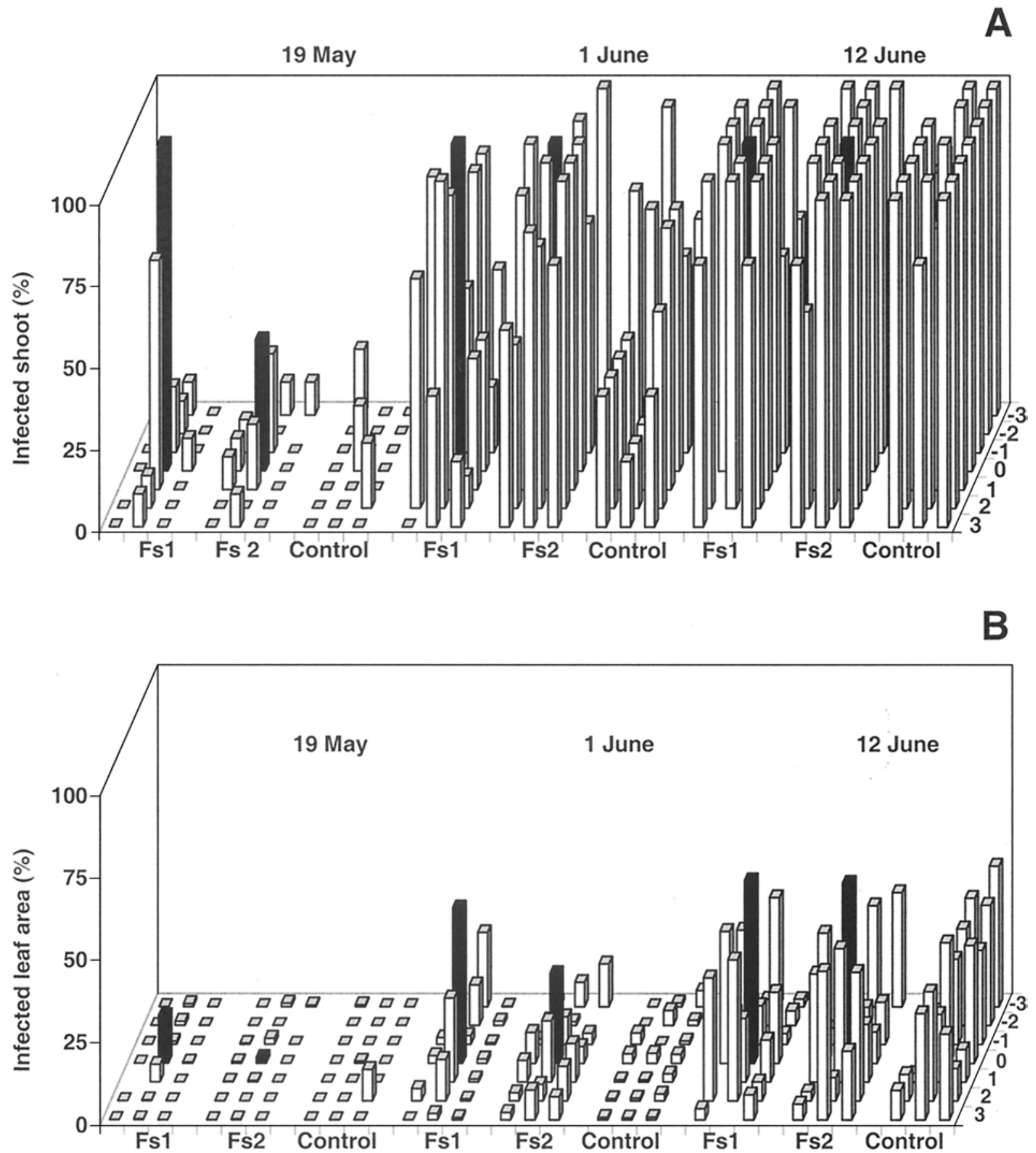

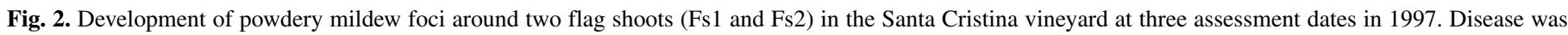

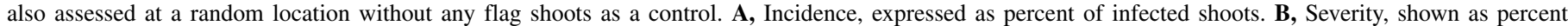

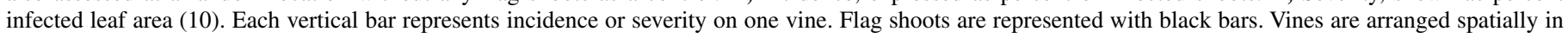
sets of three rows and are numbered -3 to 3 in relation to the vine with the flag shoot. 
Spatial analysis of flag shoots. Flag shoots were significantly aggregated within years except 1994 and 2001 when the number of flag shoots was very small (Table 1; Fig. 1). Vines with flag shoots were also significantly aggregated (data not shown). Flag shoots occurred significantly more often on the same vines in different years than what would be expected by chance $(P<$ 0.001). Moreover, flag shoots also were observed closer to flag shoots in previous years than what would be expected by chance $(P<0.05)$.

Mating type polymorphism. More than $90 \%$ of field isolates produced cleistothecia when crossed with tester isolates of one or the other mating type, allowing us to assign mating types. Mating type was polymorphic, with ratios not significantly different from $1: 1$, except in 2000 and 2001 when the sample sizes were too small for statistical tests (Table 2).

Genotypic diversity. ISSR markers from amplifications of DNA extracted from 79 isolates from Santa Cristina during 5 years were generally similar to results obtained from isolates in Australia with respect to the number and size of amplicons (38). We found between 10 and 22 polymorphic bands for each primer in our sample, for a total of 67 polymorphic loci. The presence of DNA fragments in the banding pattern of each isolate was scored for estimating allele frequencies in each sample.

Within each year, each isolate had a unique haplotype; however, two haplotypes occurred in two separate years (isolates SC97-40 and SC98-3 from 1997 and 1998 and SC98-14 and SC99-14 from 1998 and 1999). These pairs of isolates were also identical for mating type.

Spatial analysis of genotypes in flagshoots. Mating types of the flag shoot isolates were spatially random in the vineyard in 1997 and 1998 (data not shown). Once in 1997, both mating types occurred together in separate flag shoots on the same vine.

We found no evidence for the same ISSR haplotypes persisting on the same vines between years. The only two pairs of isolates with identical haplotypes persisting from one year to the next (see above) were on different vines. In one case (isolates SC98-14 and SC99-14) the distance between vines was $42 \mathrm{~m}$, while in another case (isolates SC97-40 and SC98-3) the distance was considerably shorter $(3.8 \mathrm{~m})$. Because we found only two pairs of identical haplotypes in different years, we tested if genetic distances were spatially autocorrelated. Correlations were tested for data

TABLE 2. Mating type polymorphism in flag shoot isolates of Erysiphe necator in the Santa Cristina vineyard

\begin{tabular}{lccccc}
\hline $\begin{array}{l}\text { Year of } \\
\text { sample }\end{array}$ & $N$ & ${\text { MAT }{ }^{\mathrm{a}}}$ & MAT-a & $\begin{array}{c}\text { Not } \\
\text { determined }\end{array}$ & $\chi^{\mathrm{b}}$ \\
\hline 1997 & 27 & 16 & 11 & 0 & 0.93 \\
1998 & 32 & 11 & 16 & 5 & 0.93 \\
1999 & 16 & 6 & 10 & 0 & 1.00 \\
2000 & 4 & 1 & 1 & 2 & $\ldots{ }^{\mathrm{c}}$ \\
2001 & 2 & 0 & 2 & 0 & $\ldots$ \\
\hline
\end{tabular}

${ }^{a}$ Isolates were assigned to mating types MAT+ and MAT- by successful mating with tester isolates M20 and M23 or M22 and M26, respectively.

${ }^{b}$ Number of isolates that did not mate with any tester.

c $\ldots=$ Not tested. from all years pooled, separately for 1997 and 1998, and with the 1999 to 2001 data pooled because too few isolates were recovered in each of these latter years. We found no significant correlations between haplotype distance and distance between vines with flag shoots within years $(P>0.16)$. No correlation was found between years, although there was a weak but significant negative correlation $(r=-0.16, P=0.04)$ between 1998 and the 1999 to 2001 pooled samples. This negative correlation is contrary to the expectation for a persistent clonal population, and therefore is difficult to explain biologically.

Analysis of population structure. The within-population multilocus genetic structure was not consistent with random mating in 1997 or 1998 (Table 3); sample sizes for the other years were too small to make any meaningful analyses on population structure. For both samples, the $I_{\mathrm{A}}$ and a correlation coefficient based on $I_{\mathrm{A}}$ that is independent of the number of loci analyzed $\left(\bar{r}_{d}\right)$ were significantly $(P<0.001)$ greater than expected under the null hypothesis of random mating. However, estimates of $\bar{r}_{d}$ are small, indicating a weak correlation of alleles at different loci. The proportions of locus pairs that were phylogenetically compatible were not significantly different than expected under random mating $(P>0.90$ in both years; Table 3$)$.

Two tests indicate genetic differentiation of isolates between years from the same vineyard. Significant genetic differentiation was evident between 1997 and $1998(\theta=0.049, P=0.002)$. Furthermore, haplotype similarity was significantly greater within years than when years were assigned at random $(P=0.006)$.

\section{DISCUSSION}

This study of a flag shoot subpopulation of E. necator combines epidemiology and population biology. From an epidemiological perspective, our results confirm the long-held belief that flag shoots are a significant source of primary inoculum $(33,41)$, even in populations where overwintering cleistothecia are also present $(6,19)$. Early in the epidemic, mildew focus development was clearly evident within $5 \mathrm{~m}$ of flag shoots, while disease incidence and severity were much lower on control vines. This description of disease foci, centered on flag shoots and subsequent expansion, indicate that conidia of E. necator have a relatively steep dispersal gradient similar to gradients reported for barley powdery mildew early in the epidemic (30).

Spatial autocorrelation analyses showed that vines with flag shoots are aggregated within and between years. The current hypothesis to explain this type of nonrandom pattern is that conidia disperse relatively short distances from existing flag shoots early in the epidemic when buds that give rise to the next year's shoots are still susceptible (33). Distinct disease foci around flags provide evidence not only for a steep dispersal gradient of conidia but also abundant inoculum available for infecting developing buds. Similarly, within-year aggregations may also be caused by repeated short distance dispersal of inoculum from flag shoots, causing nonrandom patterns to persist.

From a population biology perspective, we took a different approach than previous studies on flag shoot subpopulations of $E$. necator, and we can make fundamentally different inferences.

TABLE 3. Analysis of multilocus haplotypes ${ }^{\mathrm{a}}$ in the Santa Cristina vineyard in 1997 and 1998

\begin{tabular}{lcccccccc}
\hline & & & & & \multicolumn{3}{c}{ Proportion of compatible locus pairs } \\
\cline { 5 - 9 } Year & $N$ & Polymorphic loci ${ }^{\mathrm{b}}$ & $I_{\mathrm{A}}$ & $\bar{r}_{d}$ & $P^{\mathrm{c}}$ & Observed & Expected & $P$ \\
\hline 1997 & 27 & 39 & 2.19 & 0.059 & $<0.001$ & 0.44 & 0.48 & 0.989 \\
1998 & 34 & 48 & 1.93 & 0.042 & $<0.001$ & 0.39 & 0.42 & 0.999 \\
\hline
\end{tabular}

a Analyses completed with MultiLocus 1.2 (P.-M. Agapow and A. Burt, Department of Biology, Imperial College, Silwood Park, U.K.). $I_{\mathrm{A}}$ is the index of association. $\bar{r}_{d}$ is a correlation coefficient based on $I_{\mathrm{A}}$ that is independent of the number of loci analyzed. Proportion of phylogenetically compatible pairs is a measure of multilocus gametic disequilibrium. $P$ values were estimated by 1,000 randomizations.

${ }^{\mathrm{b}}$ Loci with allele frequencies $\geq 0.05$ and $\leq 0.95$ were used in this analysis.

${ }^{c} P$ values for $I_{\mathrm{A}}$ and $\bar{r}_{d}$ are identical. 
Instead of sampling only a few flag shoot isolates from each of several vineyards $(12,13,23)$, we sampled one vineyard intensively over multiple years allowing us to analyze multilocus genetic structure. We considered several models of population structure. First, we tested if populations are strictly clonal, with conidia dispersing from flag shoots and serving as inoculum that infects buds that give rise to flag shoots in the next year. This simple model was proposed on the basis of results of microscopic or visual observations of infected buds $(33,35)$, and more recently, on lack of polymorphism for mating type and failure to obtain fertile progeny from flag shoot isolates (12). Under this model, combining genetic and epidemiological data we would expect to observe the same haplotypes occurring in subsequent years and spatial and genetic autocorrelation within and between years. Although spatial aggregations of flag shoots are consistent with clonal population structure, several results contradict this simple model. Haplotypic diversity was high, with almost every isolate with a unique haplotype, and both mating types were found in 4 of the 5 years of this study in 1:1 ratios. We found little evidence for the persistence of haplotypes from one year to the next: only two of the 77 haplotypes were found more than once, both times in subsequent years. However, subpopulations were genetically differentiated between years. A similar finding was recently reported for clonal populations of Magnaporthe grisea in Korea, where haplotypes were not persistent and subpopulations were genetically differentiated between years (31). Furthermore, haplotypes were not spatially autocorrelated, even though flag shoots per se were aggregated. Evaluating this model thoroughly is complicated by the difficulty in obtaining single-conidial isolates and maintaining obligate biotrophs, thus limiting sample sizes. We successfully isolated from only 24 and $38 \%$ of the flag shoots in 1997 and 1998, respectively, making it difficult to reject this model definitively. By chance, we may not have sampled the same haplotypes multiple times because not all flag shoots were genotyped. Pruning may also cause additional random effects because it reduces the number of flag shoots potentially present within the vineyard, thereby increasing the likelihood that genetic drift causes differentiation between years. In addition, we sampled only one isolate per flag shoot, but multiple haplotypes per flag shoot would potentially increase haplotypic diversity and reduce the probability that haplotypes would be sampled more than once. More intensive sampling would be needed to address these questions further.

At the opposite extreme, we tested whether flag shoot subpopulations are randomly mating. Assuming that E. necator is heterothallic (18), ascospores that result from outcrossing are likely to have unique haplotypes (given sufficient allelic diversity), resulting in high multilocus haplotypic diversity and lack of gametic disequilibrium (25). The $I_{\mathrm{A}}$ showed significant deviations from random mating, but the proportion of locus pairs that were phylogenetically compatible was not different from expectations for random mating (Table 3), suggesting that some recombination may be occurring. High haplotypic diversity can also be caused by mutation, although mutation seems like an unlikely explanation because we consistently found the same haplotypes when isolates were recultured and genotyped independently, indicating that mutation was not high enough to be observable under laboratory conditions. However, even with relatively high mutation rates, we would expect to see similar haplotypes spatially aggregated and persisting from one year to the next if conidia from nearby flag shoots are the dominant source of inoculum for infecting buds. High diversity and lack of persistent haplotypes may also occur if new haplotypes frequently migrate into the study area and infect buds. However, immigration is not likely to result in spatial aggregation of flag shoots, nor does it agree with epidemiological evidence that disease foci form around flag shoots (producing abundant inoculum) early in the season when buds that give rise to next year's flag shoots are most susceptible to infection.
An alternative model of population structure may be that this fungus has a mixture of sexual and clonal reproduction. For example, ascospores present early in the season $(6,8,17,20)$ may potentially infect buds that give rise to flag shoots. Determining the extent of sexual and clonal reproduction from population genetic analyses is complicated by the fact that a relatively small amount of recombination is sufficient to give a population the appearance of random mating (5). Random mating is at one extreme of the mating system continuum and testing for it is often not informative for the inferring reproductive biology of fungi known to reproduce both sexually and asexually (25). For example, in this study, the proportions of phylogenetically compatible locus pairs are not different than expected under random mating (Table 3). In addition, 1:1 mating-type ratios and sexual fertility, as demonstrated in mating-type assays, together indicate the potential for sexual reproduction in this flag shoot subpopulation. These findings suggest that sexual reproduction and recombination occur in this flag shoot subpopulation. However, estimating the extent of sexual reproduction in a population is extremely challenging, requiring very large sample sizes and repeated sampling (4).

Altogether, these results are not entirely conclusive. This flag shoot subpopulation of E. necator is not predominantly clonal, nor it is randomly mating, although there is evidence for some sexual reproduction and recombination. Both reproductive modes probably occur in this flag shoot subpopulation, but additional study is needed to estimate the relative contribution of each mode.

\section{ACKNOWLEDGMENTS}

We thank the Antinori Estate for allowing us to conduct this study in their vineyard, Santa Cristina. We also thank M. Ricciolini, Agenzia Regionale Sviluppo Innovazione Agricolo-forestale-Firenze, and L. Gaspari, N. Tacconi, and E. Caporali for technical assistance with field and laboratory work.

\section{LITERATURE CITED}

1. Anderson, J. B., and Kohn, L. M. 1998. Genotyping, gene genealogies and genomics brings fungal population genetics above ground. Trends Ecol. Evol. 13:444-449.

2. Braun, U., and Takamatsu, S. 2000. Phylogeny of Erysiphe, Microsphaera, Uncinula (Erysipheae) and Cystotheca, Podosphaera, Sphaerotheca (Cystotheceae) inferred from rDNA ITS sequences - Some taxonomic consequences. Schlechtendalia 4:1-33.

3. Brown, A. D. H., Feldman, M. W., and Nevo, E. 1980. Multilocus structure of natural populations of Hordeum spontaneum. Genetics 96:523-536.

4. Brown, J. K. M., and Wolfe, M. S. 1990. Structure and evolution of a population of Erysiphe graminis f. sp. hordei. Plant Pathol. 39:376390.

5. Burt, A., Carter, D. A., Koenig, G. L., White, T. J., and Taylor, J. W. 1996. Molecular markers reveal cryptic sex in the human pathogen Coccidioides immitis. Proc. Natl. Acad. Sci. USA 93:770-773.

6. Cortesi, P., Bisiach, M., Ricciolini, M., and Gadoury, D. M. 1997. Cleistothecia of Uncinula necator-Additional source of inoculum in Italian vineyards. Plant Dis. 81:922-926.

7. Cortesi, P., Fischer, M., and Milgroom, M. G. 2000. Identification and spread of Fomitiporia punctata associated with wood decay of grapevine showing symptoms of esca. Phytopathology 90:967-972.

8. Cortesi, P., Gadoury, D. M., Seem, R. C., and Pearson, R. C. 1995. Distribution and retention of cleistothecia of Uncinula necator on the bark of grapevines. Plant Dis. 79:15-19.

9. Cortesi, P., and Milgroom, M. G. 2001. Outcrossing and diversity of vegetative compatibility types in populations of Eutypa lata from grapevine. J. Plant Pathol. 83:79-86.

10. Cortesi, P., and Ricciolini, M. 2001. L'oidio della vite in Toscana. Vol. 1/2001, Quaderno ARSIA. Firenze, Italy: ARSIA - Regione Toscana.

11. Cortesi, P., Zerbetto, F., Bisiach, M., Miazzi, M., and Faretra, F. 1999. Overwintering of Uncinula necator and epidemics of grape powdery mildew. J. Plant Pathol. 81:230.

12. Délye, C., and Corio-Costet, M.-F. 1998. Origin of primary infections of grape by Uncinula necator: RAPD analysis discriminates two biotypes. Mycol. Res. 102:283-288.

13. Délye, C., Laigret, F., and Corio-Costet, M.-F. 1997. RAPD analysis 
provides insight into the biology and epidemiology of Uncinula necator. Phytopathology 87:670-677.

14. Délye, C., Ronchi, V., Laigret, F., and Corio-Costet, M. F. 1999. Nested allele-specific PCR primers distinguish genetic groups of Uncinula necator. Appl. Environ. Microbiol. 65:3950-3954.

15. Evans, K. J., Scott, E. S., and Whisson, D. L. 1997. Heterothallism among South Australian clonal lines of Uncinula necator. Australas. Plant Pathol. 26:10-20.

16. Evans, K. J., Whisson, D. L., and Scott, E. S. 1996. An experimental system for characterizing isolates of Uncinula necator. Mycol. Res. 100:675-680.

17. Gadoury, D. M., and Pearson, R. C. 1990. Germinaton of ascospores and infection of Vitis by Uncinula necator. Phytopathology 80:1198-1203.

18. Gadoury, D. M., and Pearson, R. C. 1991. Heterothallism and pathogenic specialization in Uncinula necator. Phytopathology 81:1287-1293.

19. Halleen, F., and Holz, G. 2000. Cleistothecia and flag shoots: Sources of primary inoculum for grape powdery mildew in the Western Cape province, South Africa. S. Afr. J. Enol. Vitic. 21:67-70.

20. Jailloux, F., Willocquet, L., Chapuis, L., and Froidefond, G. 1999. Effect of weather factors on the release of ascospores of Uncinula necator, the cause of grape powdery mildew, in the Bordeaux region. Can. J. Bot. 77:1044-1051.

21. Kohli, Y., Brunner, L. J., Yoell, H., Milgroom, M. G., Anderson, J. B., Morrall, R. A. A., and Kohn, L. M. 1995. Clonal dispersal and spatial mixing in populations of the plant pathogenic fungus, Sclerotinia sclerotiorum. Mol. Ecol. 4:69-77.

22. Maynard Smith, J., Smith, N. H., O'Rourke, M., and Spratt, B. G. 1993. How clonal are bacteria? Proc. Natl. Acad. Sci. USA 90:4384-4388.

23. Miazzi, M., Hajjeh, H., and Faretra, F. 2003. Observations on the population biology of the grape powdery mildew fungus Uncinula necator. J. Plant Pathol. 85:123-129.

24. Miazzi, M., Natale, P., Pollastro, S., and Faretra, F. 1997. Handling of the biotrophic pathogen Uncinula necator (Schw.) Burr. under laboratory conditions and observations on its mating system. J. Plant Pathol. 79:71-77.

25. Milgroom, M. G. 1996. Recombination and the multilocus structure of fungal populations. Annu. Rev. Phytopathol. 34:457-477.

26. Milgroom, M. G., and Cortesi, P. 1999. Analysis of population structure of the chestnut blight fungus based on vegetative incompatibility genotypes. Proc. Natl. Acad. Sci. USA 96:10518-10523.

27. Milgroom, M. G., and Lipari, S. E. 1995. Spatial analysis of nuclear and mitochondrial RFLP genotypes in populations of the chestnut blight fungus, Cryphonectria parasitica. Mol. Ecol. 4:633-642.

28. Milgroom, M. G., MacDonald, W. L., and Double, M. L. 1991. Spatial analysis of vegetative compatibility groups in the chestnut blight fungus, Cryphonectria parasitica. Can. J. Bot. 69:1407-1413.

29. Milgroom, M. G., and Peever, L. T. 2003. Population biology of plant pathogens: the synthesis of plant disease epidemiology and population genetics. Plant Dis. 87:608-617.

30. O'Hara, R. B., and Brown, K. M. 1998. Movement of barley powdery mildew within field plots. Plant Pathol. 47:394-400.

31. Park, S.-Y., Milgroom, M. G., Han, S. S., Kang, S., and Lee, Y.-H. 2003. Diversity of pathotypes and DNA fingerprint haplotypes in populations of Magnaporthe grisea in Korea over two decades. Phytopathology 93: 1378-1385.

32. Pearson, R. C., and Gadoury, D. M. 1987. Cleistothecia, the source of primary inoculum for grape powdery mildew in New York. Phytopathology 77:1509-1514

33. Pearson, R. C., and Gärtel, W. 1985. Occurrence of hyphae of Uncinula necator in buds of grapevine. Plant Dis. 69:149-151.

34. Pearson, R. C., and Goheen, A. C., eds. 1988. Compendium of Grape Diseases. The American Phytopathological Society, St. Paul, MN.

35. Sall, M. A., and Wrysinski, J. 1982. Perennation of powdery mildew in buds of grapevines. Plant Dis. 66:678-679.

36. Shah, D. A., Bergstrom, G. C., and Ueng, P. P. 2001. Foci of Stagonospora nodorum blotch in winter wheat before canopy development. Phytopathology 91:642-647.

37. Stenlid, J., Karlsson, J.-O., and Hogberg, N. 1994. Intraspecific genetic variation in Heterobasidion annosum revealed by amplification of minisatellite DNA. Mycol. Res. 98:57-63.

38. Stummer, B. E., Zanker, T., and Scott, E. S. 2000. Genetic diversity in populations of Uncinula necator: Comparison of RFLP- and PCR-based approaches. Mycol. Res. 104:44-52.

39. Weining, S., and Langridge, P. 1991. Identification and mapping of polymorphisms in cereals based on the polymerase chain reaction. Theor. Appl. Genet. 82:209-216.

40. Weir, B. S. 1996. Genetic data analysis II. Sinauer, Sunderland, MA.

41. Ypema, H. L., and Gubler, W. D. 2000. The distribution of early season grapevine shoots infected by Uncinula necator from year to year: A case study in two California Vineyards. Am. J. Enol. Vitic. 51:1-6. 